\title{
Performance Analysis of Micro-Grid Based On Measurement and Processing Different Electrical Quantities
}

\author{
Ihsan Mizher Baht ${ }^{1}$, Petre-Marian Nicolae ${ }^{1}$, Nameer Bahat ${ }^{2}$ \\ ${ }^{1}$ Department of Electrical Engineering-Craiova, Romania \\ ${ }^{2}$ Department of computer science, Universities west of Timisoara, Romania
}

\begin{abstract}
To change the electrical power system from conventional system or existing system to micro grid one needs to check the performance of this system and analyze all parameters. Actually the power grid consists of three essentials parts that are generation, transmutation line and distributions system. Among all parts feeders, transformers and some of electronics parts are to improve the voltage drop or decrease the active power losses and interfaces between two systems. The main advantage of the micro grid is integration of the renewable energy recourses into the power grid through transmutation line or distribution system, but before integration one needs to check and evaluate all parameters of the system (cable, transformers, load flow, losses, etc.). and find out how to improve them . This paper consists of three parts: the first part is introduction about important parameters in the power grid, the Second part analyzes system from IEC standers by using MATLAB software and discuss on the result of these systems. as well as it involves an idea of how to improve it by using the Newton Raphson method. The third part is about power quality analysis and effect of the harmonics on the current and voltage wave form.
\end{abstract}

Keywords - micro grid, renewable energy, control power flow, MATLAB.

DOI:10.18421/TEM93-01

https://doi.org/10.18421/TEM93-01

Corresponding author: Ihsan Mizher Baht, Department of Electrical Engineering-Craiova, Romania. Email: imb121378@yahoo.com

Received: 11 June 2020.

Revised: 24 July 2020.

Accepted: 31 July 2020.

Published: 28 August 2020.

(c) Br-NC-ND (C) 2020 Ihsan Mizher Baht, Petre-Marian Nicolae \& Nameer Bahat; published by UIKTEN. This work is licensed under the Creative Commons AttributionNonCommercial-NoDerivs 4.0 License.

The article is published with Open Access at www.temjournal.com

\section{Introduction}

Despite the fact that there are many aspects and issues of emphasis that characterize the functional framework of micro-grid systems, the optimal energy interaction between the MG (smart grid) and power energy system are included to improve the performance of the all system parameters [16],in which the analysis of performance is one of the most important issues of emphasis, and its change during the time and resources [11]. Unless micro-grid systems are aligned towards a reliable and effective blueprint for performance analysis, it then follows the attainment of the intended level of functionality, which is undermined extensively. When it comes to the actualization of the blueprint for performance analysis, it is vitally important to accentuate the fact that two elements have to be accentuated upon. These elements are measurement as well as processing of different electrical quantities. The two platforms constitute an integral element on which the entire mechanism for the performance analysis. and micro-grid systems is actualized. This is the focus of this research whereby load flow analysis and optimal power flow are also evaluated extensively.

\section{Integrating Renewable Energy Resources}

The $49 \%$ of the electrical demands on the world will be increasing in 2035 [7]. The benefit of the integration RES can be named as fast installation, high power quality, less pollution and increasing energy efficiency [1].The ways in which different electrical quantities can be aligned towards the blueprint of performance analysis also encompasses the analysis of flow of power. Depending on the manner in which power is flowing within a system, it can be deemed as being effective or ineffective. In the event that the process with which the flow of power is actualized is ineffective, then the entire system cannot be categorized or classified as being reliable [4]. Within the confines of the selected case, it is evident that there is extensive emphasis on 
renewable energy. In essence, there are various ways in which the flow of power in this system has been enhanced through the use of renewable energy. Firstly, this system has greatly reduced the total inputs that are aligned into the grid. Always this vital aspect plays an integral role towards the attainment of success in the short-term as well as in the longterm. It is also evident that the application of renewable energy has promoted the extent to which load flow is optimized especially as far as capacitance is concerned. These stipulations are immensely beneficial in that they promote the system's viability in the long-run. In view of these elements, it is hence evident that the selected case is a highly effective model that can be applied across different contexts in the short-term as well as in the long-term.

\section{Performance Analysis of Micro-Grid}

For any micro-grid system that is to be considered as being effective, there is always the need to ensure that it does not contribute towards the degradation of the environment. In the event that a system pollutes the environment, it then follows that such a system cannot be considered as being effective and reliable [5]. When it comes to the promotion of the effectiveness with which micro-grid systems performs, to keep the system operating at the optimal point controller has to. Investigate the system under different power flow load and different type of load [13], while the issue of optimal capacitor placement also serves as a notable aspect of emphasis. In essence, there is the need to accentuate the fact that there are various ways in which the nexus between the performances of micro-grid systems is impacted by the optimal placement of capacitors. In essence, while some of the implications are direct, others are more or less indirect. In line with such aspects, there is always the need for such nexus and connectivity to be inculcated into the framework of planning so as to promote the effectiveness with which the intended outcomes are attained.

Based on these stipulations, one of the main ways in which the performance of micro-grid systems is impacted by the optimal placement of capacitors pertains to the issue of power output [10]. Within the confines of a micro-grid system, the level of output is always one of the most important aspects of performance. In the event that the system is not characterized by a high level of output, it means that the framework of performance cannot be considered as being desirable. On the other hand, the attainment of a high level and standard of output serves as an indicator of the fact that the entire system can be relied upon. In line with such an aspect, it is hence evident that output has to be assessed when determining the ways or manner in which the performance of micro-grid systems is impacted by the optimal placement of capacitors. Unless such an aspect is taken into consideration, the precise level or standard of performance cannot be developed as aptly as possible.

In addition to output, another notable aspect of emphasis that has to be always considered within the context of the performance of micro-grid systems is impacted by the optimal placement of capacitors pertains to the overall level of reliability. This is because of capacitors, which have direct ramifications on the extent to which a system is reliable. In essence, this not only applies in the shortterm, but also in the long-term. In the event that the relevant systems and mechanisms are not developed for the promotion of the standards of reliability within a micro-grid system, it means that the intended outcomes are complex to attain.

The ways in which the performance of micro-grid systems is impacted by the optimal placement of capacitors can be evaluated also encompasses the issue of applicability across different areas. The purpose of any system is usually to serve as many users as possible. In the event that this cannot be attained, it the overall level of reliability of the grid is compromised. In line with such an aspect, we can add that there is always the need to evaluate the extent to which a grid can be applied or used within a given area [6]. This is usually beneficial in that it goes a very long way towards the quantification of the manner in which the performance of micro-grid systems is impacted by the optimal placement of capacitors. These elements are hence indicative of the manner in which the two overlap.

The issue of capacitor bank is also vital when it comes to the entire mechanism of determining the performance levels of a micro-grid system. One of the main ways in which the performance is connected to capacitor bank is that the latter plays an integral role towards determining the amount of power or electric energy that can be processed at any given time. This is immensely influential since it has longterm implications on the success of the system in the long-run. This is always an important aspect that has to be aligned towards the blueprint of decision making and planning when it comes to the use and application of a system.

The connection between the performance levels of a micro-grid system and capacitor bank is that it determines the extent to which the existing energy can be backed up. This is an influential element of any system considering that it has pertinent implications on the overall extent to which the performance of the system is optimized. In the absence of an effective and reliable capacitor bank, it can be complex for the intended quality of outcomes. 
Which are to be attained as far as the performance of the system is concerned [9]. Based on these stipulations, it is hence evident that there is always the need for the performance levels of a micro-grid system to be aligned towards the evaluation of the extent to which capacitors are adequately optimized. This is also immensely pertinent as far as risk management and prevention is concerned.

The energy management problem is defined as power generation, consumption as well as the effect of power unit with the utility by the direct and indirect effect [12], then it is defined as the subject and objective of the system controller [17].

\section{Case Stady}

In the grid operation the comparison between the demand power with supply and the balance between them is one of the important factor operation in the power system [14].To determine the performance of the system one has to analyze all the parameters of circuits for example voltage, angle, losses, cable size, etc., When the control voltage is compromised, the overall performance levels of a micro-grid system are low. This is because of the far-reaching implications of control on the level of output [3].

MG (content PV, WT...etc.) is considered to reach to the optimal operation and increase the quality and reliability [2]. Analysis of the MG (case study) consists of many steps, in which the first case there is nine buses from IEEE standers shown in Figure 1. Second example shows the configuration of the circuit IEC standards in the Figure 2. (Connection the solar cells to the system by DC. Link).

Table 1. Power Flow

\begin{tabular}{|c|c|c|c|c|c|}
\hline \multirow{2}{*}{$\begin{array}{l}\text { BRANCH } \\
\text { ID }\end{array}$} & \multicolumn{2}{|c|}{ FROM TO BUS } & \multicolumn{2}{|c|}{ LOSSES } & $V$ BUS \\
\hline & MW & Mvr & $\mathrm{KW}$ & KVAR & V \\
\hline TI & 0.233 & 0.047 & 0.4 & 1.8 & 99.6 \\
\hline $\mathrm{T} 2$ & 0.121 & 0.012 & 0.15 & 0.5 & 99.5 \\
\hline XF04 & 0.408 & 0.283 & 0.6 & 6.7 & 99.6 \\
\hline CABLE 1 & -4.251 & -3.53 & 2.5 & -30.6 & 99.9 \\
\hline XFM1 & 4.251 & 3.53 & 8.9 & 161.5 & 99 \\
\hline $\begin{array}{l}\text { CABLE } \\
\text { MAIN }\end{array}$ & -0.01 & -0.006 & 0 & 0 & 100 \\
\hline TX5 & 2 & -0.443 & 5.4 & 66.5 & 100 \\
\hline XFM2 & -0.01 & -0.006 & 0 & 0 & 100 \\
\hline XFM3 & 2.893 & 1.263 & 4.6 & 66.5 & 99 \\
\hline & & & $\begin{array}{l}\text { TOTAL } \\
22.2\end{array}$ & $\begin{array}{l}\text { LOSSE } \\
273.2\end{array}$ & \\
\hline
\end{tabular}

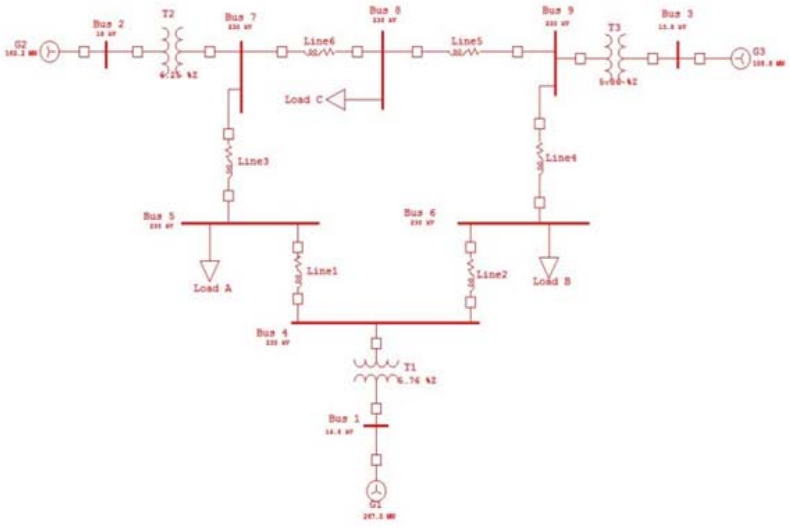

Figure 1. IEEE 9 BUS

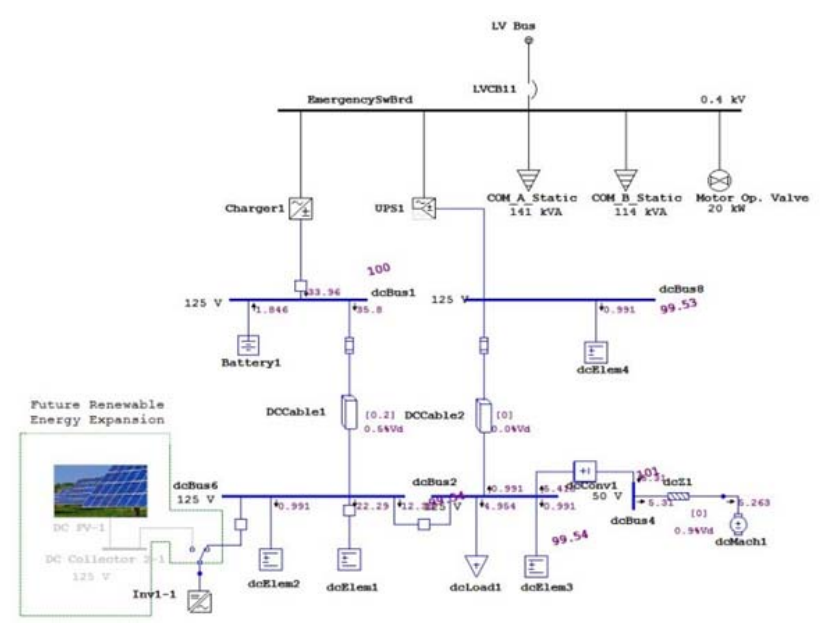

Figure 2. Connect the solar cells to the system IEC standers.

IEC standard circuits include two sub circuits one for low voltage and other for DC circuit, shown in Figure4, as well as the configuration of the IEC circuits.

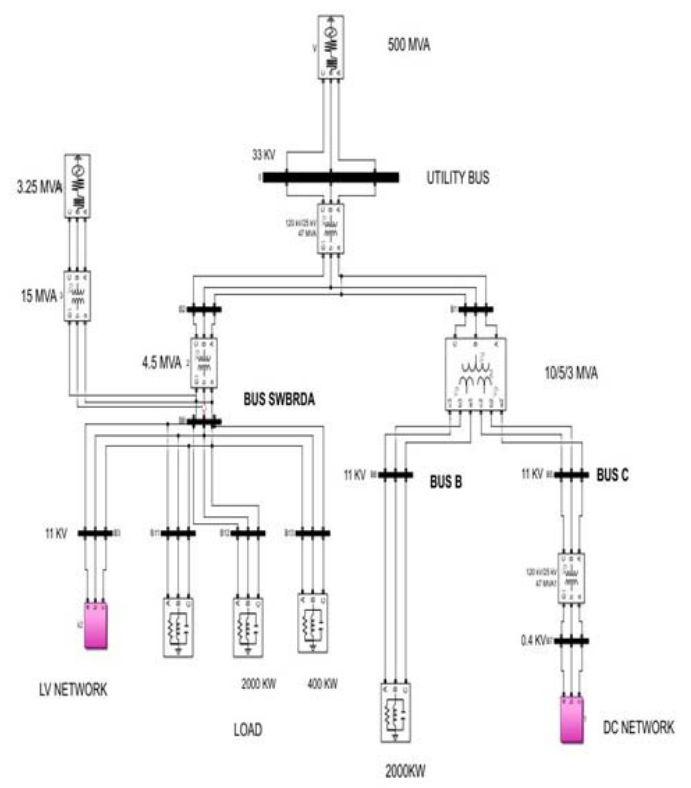

Figure 3. IEC Standers model anlysis by Matlab sumlink. 


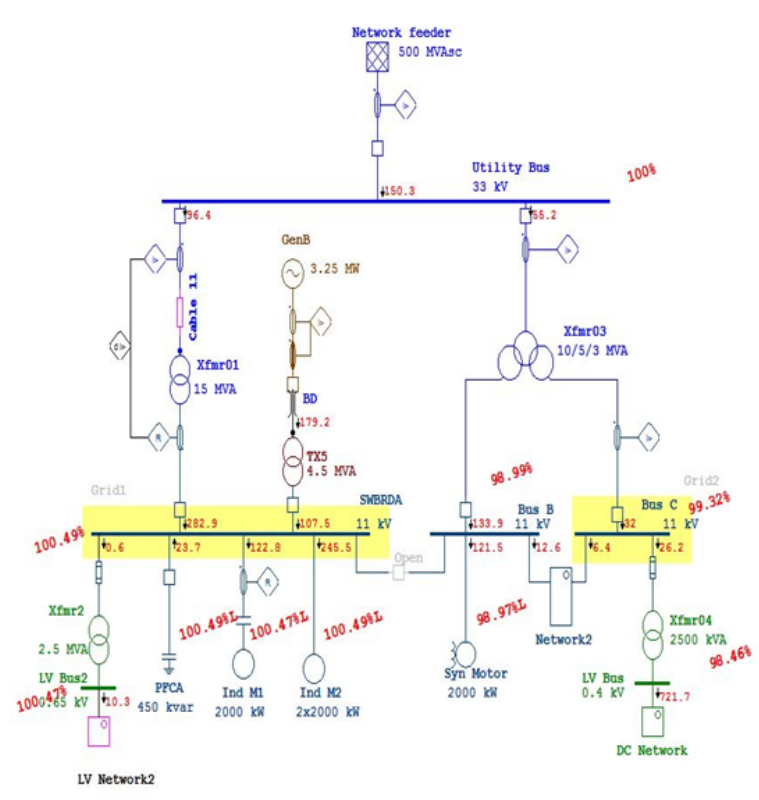

Figure 4. IEC Standers Circuit.

By using Newton Raphson Method with 99 iterations, the load flow analysis for both AC and DC networks to determine Generation Loading Demand, Branch load and losses. Branch connection and feeder capacity, alert report, etc. All the factors, parameters and results above give us the ability to evaluate and improve the network.

After analysis the systems above, here are the performance results:

1- Bus Loading.

2- Branch loading.

3- Losses.

4- Cable.

5- Power factor.

6- Voltage drops.

7- Power flow.

8- Transformer limit.

9- Generator operation and demand.

Table 1 shows the losses of all Buses, bus voltage, and active, or reactive power flow, Table 2 shows the voltage magnitude, angle for each buses, voltage drop and power factor.

\section{Power Quality}

Integration the RES has advantage and disadvantage, and the main advantage reduce the power losses through connected RES to the distribution system directly [15]. One of the most notable ways in which the nexus between performance analysis of a micro-grid system is aligned towards optimal power flow as well as load flow analysis is evident pertains to the fact that the two elements plays an integral role towards determining the total amount of energy that reaches the user [8]. Monitoring the Operation of the supply power generation for each terminal power supply, current at the steady state and of transit stability one of very important indicator to consider the system is to secure.

Electrical Power generation is produced from the generation $\mathrm{B}$,which is about $2 \mathrm{MW}$, while the system generation at the steady state after $2 \mathrm{sec}$ determaine the power qualty (voltage,harmounics, and power factor ) and improve the need to anlyze the system than choose the method to support it which is shown in Table 1 and Table 2 The best way to improve the voltage, $\mathrm{PF}$,reactive power flowand decres the losses by the opimal capactior (palcament, size, location, connection, ccontrol ).

Table 2. Voltage Mag.And Angle

\begin{tabular}{|c|c|c|c|c|c|c|}
\hline Bus & \multicolumn{2}{|c|}{ voltage } & \multicolumn{2}{|l|}{$\begin{array}{l}\text { load } \\
\%\end{array}$} & $\mathrm{pf}$ & load \\
\hline ID & Mag & Ang. & MW & MVAR & & \\
\hline Bus B & 98.99 & -1.2 & 2.126 & 0.855 & 93.4 & 59.5 \\
\hline Bus C & 99.32 & -0.7 & 0.0 & 0 & 87.3 & 14.2 \\
\hline Bus 3 & 99.94 & 0.0 & 0.0 & 0 & 76.9 & \\
\hline Bus 5 & 100.4 & -1.3 & 0.01 & 0.006 & 86.9 & \\
\hline Bus 6 & 100 & 0.6 & 0 & 0 & 97.6 & \\
\hline ESW & 98.4 & -1.3 & 0.408 & 0.276 & 82.8 & 60.1 \\
\hline $\begin{array}{c}\text { LV } \\
\text { BUS }\end{array}$ & 98.46 & -1.3 & 0 & 0 & 82.8 & 60.1 \\
\hline $\begin{array}{c}\text { LV } \\
\text { BUS } 2\end{array}$ & 100 & -1.3 & 0 & 0 & 86.9 & \\
\hline MCC1 & 98.74 & -1.63 & 0.233 & 0.045 & 98.2 & \\
\hline SW2 & 99.23 & -0.9 & 0.121 & 0.012 & 99.5 & \\
\hline SW & 100.4 & -1.3 & 6.227 & 2.853 & 85.3 & 30.6 \\
\hline $\begin{array}{l}\text { Utility } \\
\text { bus }\end{array}$ & 100 & 0 & 0 & 0 & 82.2 & 18.8 \\
\hline
\end{tabular}

The Harmonics distortions for the voltage and current big factors to determine the efficiency of the system.

From the system above Figure 3 shows IEC standards, selected the Buses consisting of motors as the loads, electronic devices, inductions motors load, and utilities of Bus. In this types of loads the harmonics effect is high than in other buses.

The Buses is:-

1- Bus A includes synchronous motor of $2000 \mathrm{kw}$, shown in Figure 5.

2- Bus B includes de network with PV array shown in the Figure 6.

3- Bus C includes LV network and 3motors shown in the Figure 7.

4- Bus D utility of the main bus, which has $33 \mathrm{kv}$. 


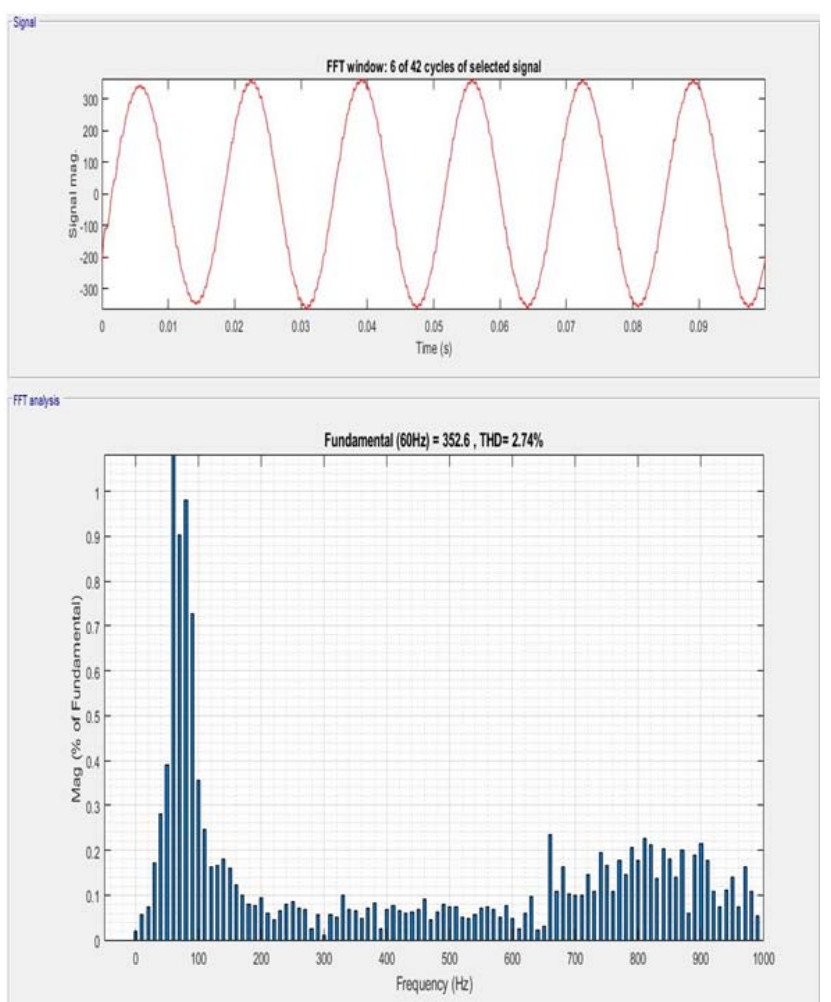

Figure 5. Voltage Wave Bus A.
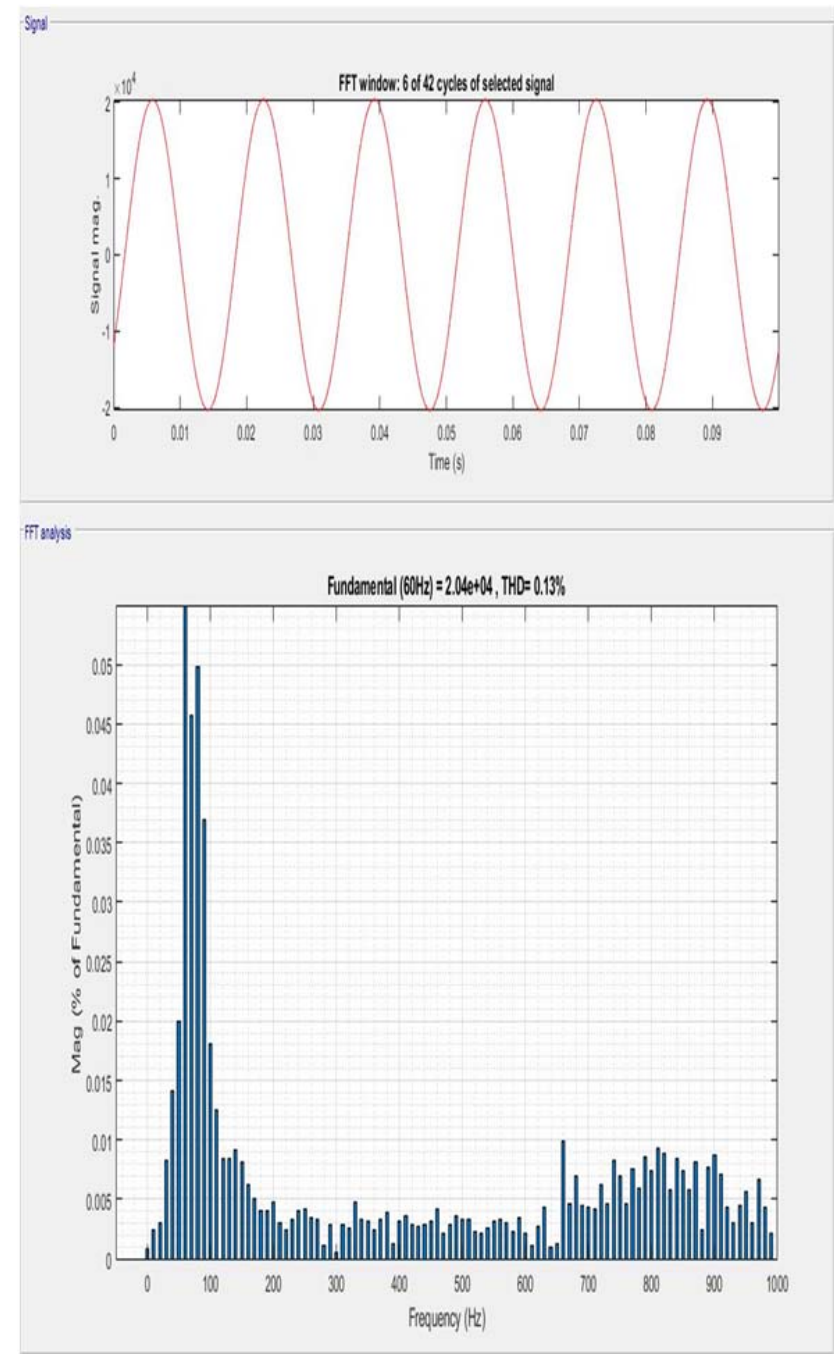

Figure 6. Voltage Wave Bus B..
In the Figure 8 there are the comparations among the four Buses above and the effect of the last two Buses (utity Bus and SW Bus), which is bigger than the first and second Buses since the Harmonics distortions are due to the electroincs part and low voltage buses are more than those with high and meidium voltage. Table 3 . shows the total harmounics distoration of VTHD with voltage rating and fundumantal percentage.

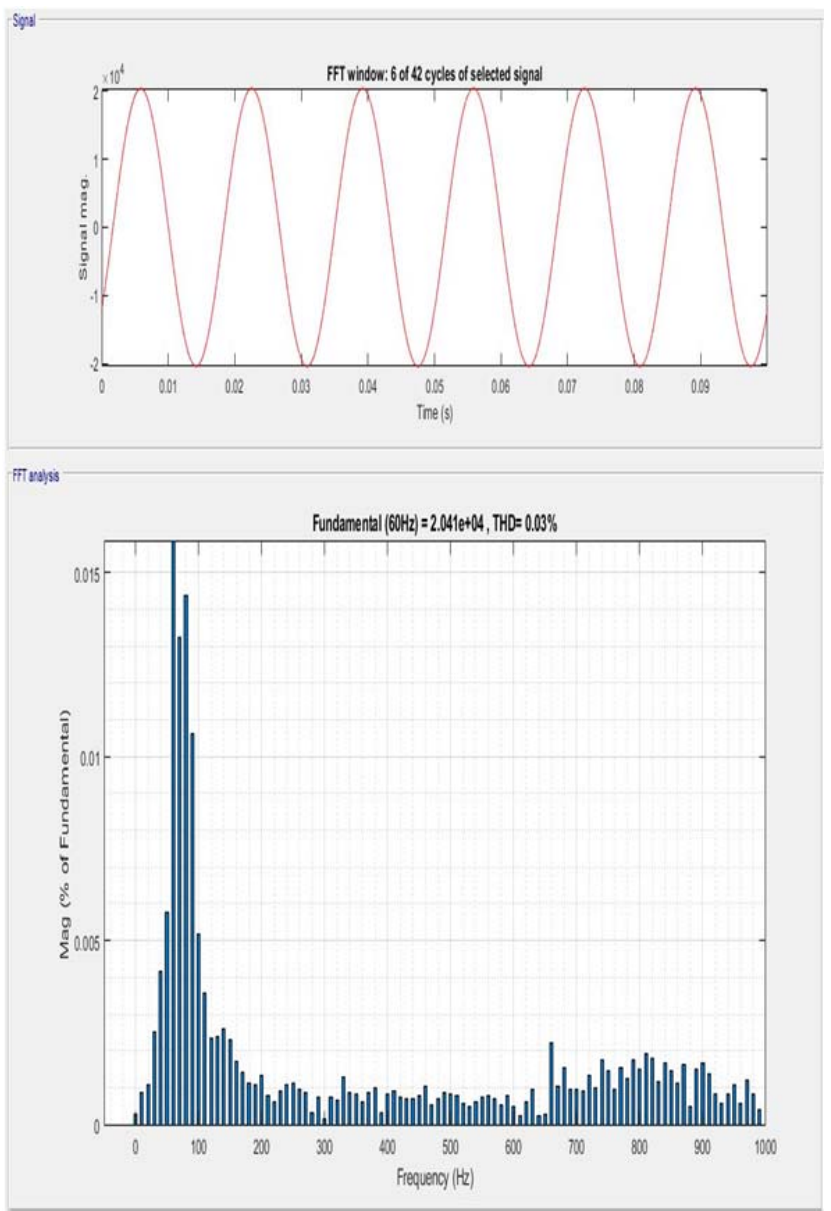

Figure 7. voltage wave $C, L V$ bus

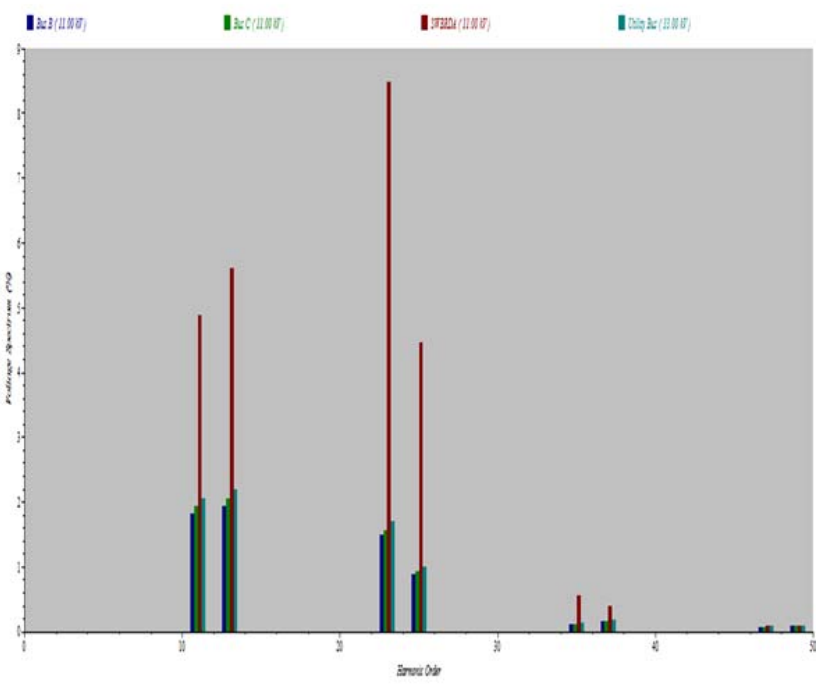

Figure 8. Spectrum Comparators 
Table 3. Total Harmonics Distortion

\begin{tabular}{|c|c|c|c|}
\hline \multirow{2}{*}{ Bus } & \multicolumn{3}{|c|}{ Voltage distortion } \\
\hline ID & $\mathrm{kV}$ & Fund \% & VTHD \% \\
\hline Bus B & 11 & 99.01 & 3.20 \\
\hline Bus C & 11 & 99.34 & 3.37 \\
\hline Bus 3 & 33 & 99.94 & 3.69 \\
\hline Bus 5 & 0.650 & 100.43 & 12.05 \\
\hline Bus 6 & 6.600 & 100 & 9.56 \\
\hline Em.Sw & 0.4 & 98.57 & 3.31 \\
\hline LV Bus & 0.4 & 98.57 & 3.31 \\
\hline LV Bus2 & 0.650 & 100.47 & 12.65 \\
\hline Mcc1 & 0.4 & 98.76 & 3.05 \\
\hline Utility Bus & 33 & 100 & 3.59 \\
\hline
\end{tabular}

\section{Economic Assessment}

Quality, time and cost are the main factors that make the power system with high reliability. Calculating the best financial returns as decreeing energy losses, economic assessment done by connecting the capacitor bank into system need analysis make the cost of installation and saving power possible.

Table 4 shows the optimal capacitor placement cost summary.

Table 4. OPC Cost

\begin{tabular}{|c|c|c|c|c|c|}
\hline \multicolumn{3}{|c|}{ Cost \$ } & \multicolumn{3}{c|}{ Saving \$ } \\
\hline Year & $\begin{array}{c}\text { install } \\
\text { ing }\end{array}$ & Oper. & $\begin{array}{c}\text { Loss } \\
\text { reduc. }\end{array}$ & $\begin{array}{c}\text { Yearl. } \\
\text { prof. }\end{array}$ & $\begin{array}{c}\text { Acuma. } \\
\text { prof }\end{array}$ \\
\hline 1 & 5600 & 500 & -111.85 & -6211 & -6211 \\
\hline 2 & 0 & 500 & -111.85 & -611 & -6823 \\
\hline 3 & 0 & 500 & -111.85 & -611 & -7435 \\
\hline 4 & 0 & 500 & -111.85 & -611 & -8047 \\
\hline 5 & 0 & 500 & -111.85 & -611 & -8659 \\
\hline
\end{tabular}

Figure 9 shows the profile during the planning periods for the five years. The accumulative saving from the table above and the Figure 13 is $8659.000 \$$. The cost of the installation capacitor is $5600 \$$ for the one years, and the load flow analysis calculate the total losses with and without capacitor bank, and the average power cost is approximately $0.07 / \mathrm{kWh}$ than the losses reduced for one year which is $111.85 \$$.

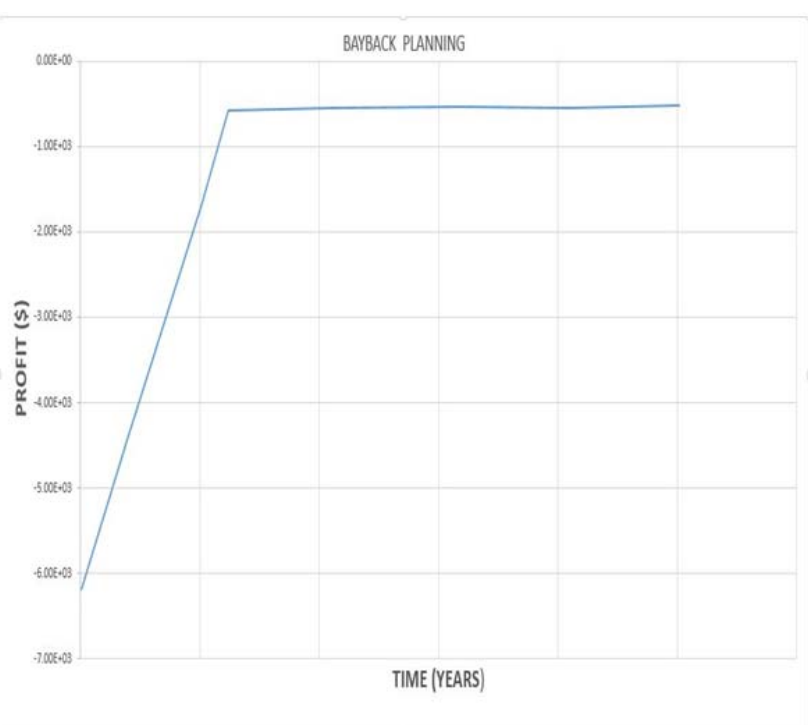

Figure 9. The Profile during the Planning Period

Figure 10 shows the system improved by installation of the OPC in the IEC standard system and adjusted voltage from $98 \%-102 \%$. which reduces the losses. Reactive power of OPC is enhancing and improves the system harmonics.

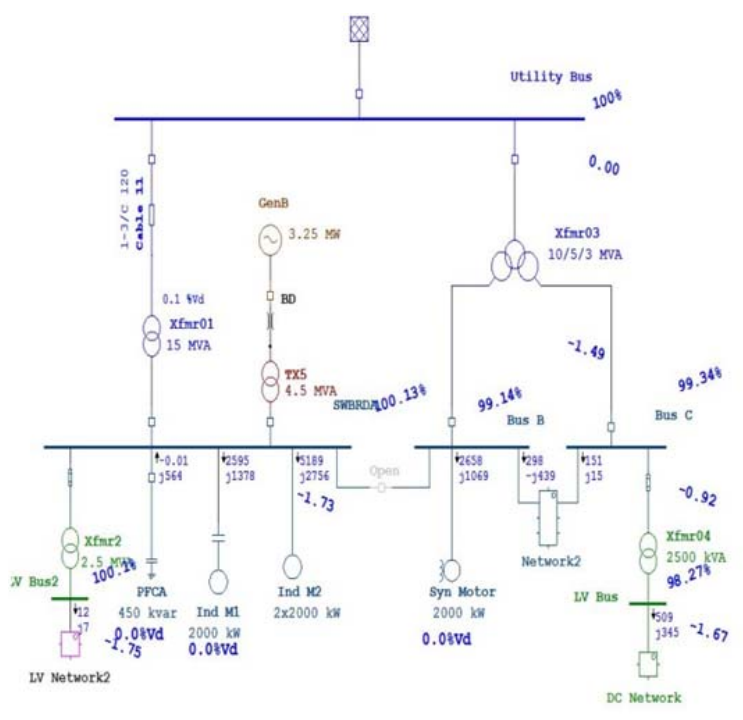

Figure 10. The System Improve It By Installation The OPC.

The main objective for all analysis and improvement methods to monitoring and control the performance of the power grid and utilities system, determine the minimum and maximum load with saving the load by using OPC.

\section{Conclusion}

In this paper we focused on analysis within the system and on how to improve it by using load flow analysis (newton Raphson method) including the case of IEC standard system for analysis, and capacitor bank in order to improve the voltage distortions and decreasing the harmonic effect. 
Economic assessment is one of very important factors that determine the income from installing of the capacitors bank toward its benefits (cost, energy saving). These steps help and supports the strategies to develop the conventional grid to micro or smart grid.

\section{References}

[1]. Abbasi, A., Abbasi, S., Ansari, J., \& Rahmani, E. (2015). Effect of plug-in electric vehicles demand on the renewable micro-grids. Journal of Intelligent \& Fuzzy Systems, 29(5), 1957-1966.

[2]. Abdi, H., Moradi, A., \& Saleh, S. (2015). Optimal unit commitment of renewable energy sources in the micro-grids with storage devices. Journal of Intelligent \& Fuzzy Systems, 28(2), 537-546.

[3]. Adam, R., \& Wintersteller, W. (2008). European Smart Grid Faces Different Hurdles From United States. Natural Gas \& Electricity, 25(3), 13-18.

[4]. Bae, J. W., \& Kim, H. R. (2018). Feasibility and its characteristics of $\mathrm{CO} 2$ laser micromachining-based PMMA anti-scattering grid estimated by MCNP code simulation. Journal of X-Ray Science and Technology, 26(2), 273-280.

[5]. Basu, A. K., Chowdhury, S., \& Chowdhury, S. P. (2010). Value-based operational strategy at the planning of CHP-based micro-grid. Int $J$ Energy Environ, 1(5), 871-882.

[6]. Fedele, R., Ciani, A., Galantucci, L., Bettuzzi, M., \& Andena, L. (2013). A regularized, pyramidal multigrid approach to global 3D-volume digital image correlation based on X-ray microtomography. Fundamenta Informaticae, 125(3-4), 361-376.

[7]. Mumtaz, S., \& Khan, L. (2017). Adaptive control paradigm for photovoltaic and solid oxide fuel cell in a grid-integrated hybrid renewable energy system. PloS one, 12(3), e0173966.
[8]. Mumtaz, S., Khan, L., Ahmed, S., \& Bader, R. (2017). Indirect adaptive soft computing based wavelet-embedded control paradigms for $\mathrm{WT} / \mathrm{PV} / \mathrm{SOFC}$ in a grid/charging station connected hybrid power system. PloS one, 12(9), e0183750.

[9]. Porobić, V. B., Adžić, E. M., \& Rapaić, M. R. (2016). HIL evaluation of control unit in grid-tied coverters. Thermal Science, 20(suppl. 2), 393-406.

[10]. Sharma, P. P., Chatterji, S., \& Singh, B. (2013). Techno-economic analysis and modelling of standalone versus grid-connected small hydro-power systems-a review of literature. International Journal of Sustainable Energy, 32(1), 1-17.

[11]. Van Nieuwpoort, R. V., Wrzesińska, G., Jacobs, C. J., \& Bal, H. E. (2010). Satin: A high-level and efficient grid programming model. ACM Transactions on Programming Languages and Systems (TOPLAS), 32(3), 1-39.

[12]. Taherpoor, H., Niknam, T., \& Kavousi-Fard, A. (2015). A novel stochastic framework for energy management in renewable micro-grids considering uncertainty of measurement and forecasting. Journal of Intelligent \& Fuzzy Systems, 28(3), 999-1008.

[13]. Vosoogh, M., Kamyar, M., \& Akbari, A. (2014). A novel modification approach based on MTLBO algorithm for optimal management of renewable micro-grids in power systems. Journal of Intelligent \& Fuzzy Systems, 27(1), 465-473.

[14]. Wang, S., Xue, X., \& Yan, C. (2014). Building power demand response methods toward smart grid. HVAC\&R Research, 20(6), 665-687.

[15]. Zare, J., \& Zare, A. (2015). An intelligent stochastic method based on fuzzy cloud theory for modeling uncertainty effects in the renewable microgrids. Journal of Intelligent \& Fuzzy Systems, 28(1), 421-431.

[16]. Zeiler, W., \& Boxem, G. (2013). Smart GridBuilding Energy Management System: An Ontology Multi-agent Approach to Optimize Comfort Demand and Energy Supply. ASHRAE Transactions, 119, H1.

[17]. Zeiler, W., Vissers, D., \& Boxem, G. (2013). A new smart micro grid process control strategy: the human leading the thermal comfort control. ASHRAE Transactions, 119, I1. 